\title{
Thoughts on the Function of Community Education from the Perspective of Policy Network During the Epidemic Period
}

\author{
Yu Liu ${ }^{1 *}$ \\ ${ }^{1}$ School of Political Science and Law, University of Jinan \\ *Corresponding author. Email: 2741026764@qq.com

\begin{abstract}
At present, when COVID-19 has become a global "pandemic", only by keeping the defense line of community can we effectively cut off the channels for the spread of the epidemic. Taking the epidemic situation as an opportunity, starting from the study of community governance, this paper reconsiders the function of community education in order to better promote community governance and improve the national emergency response capability.
\end{abstract}

Keywords: Community Governance, Policy Network Theory, Community education

\section{INTRODUCTION}

\subsection{Research background}

The sudden outbreak of novel coronavirus before the Spring Festival in 2020 is the most influential public health emergency in the history of New China, and no one can stay out of it. On January 20, the National Health and Wellness Committee issued an announcement to include new crown pneumonia in Class B infectious diseases and take preventive and control measures for Class A infectious diseases ${ }^{[1]}$. Although with the strengthening of prevention and control, the prevention and control force gradually sinks to the community, the community prevention and control of epidemic has made great progress. However, at present, community prevention and control is still faced with the hard constraints of few resources, great pressure and complicated situation. There are also problems such as insufficient strength of grass-roots staff, lack of adequate medical protection, serious shortage of professional strength, inability to provide professional guidance and services for the isolated people at home, and lack of attention to residents' emotional counselling and psychological construction ${ }^{[2]}$. As a means of social governance, policy is of great significance to community prevention and control ${ }^{[3]}$, The process of community governance is gradually developing into a typical policy network ${ }^{[4]}$. Therefore, the reasons of community governance during the epidemic and related improvement measures are analysed from the perspective of policy network.

\subsection{Research significance}

At the moment when Covid-19 has become a global "pandemic", it is urgent to raise awareness of guard and actively prevent and control it. Community is the front line of joint prevention and control of epidemic situation, and it is also the most effective line of defense against external input and internal non-proliferation. Only by keeping this line of defense in the community can we effectively cut off the spread of the epidemic ${ }^{[5]}$. Community prevention and control is extremely important because communities are the cells and units of society and the basic fortress for the whole epidemic prevention and control work ${ }^{[6]}$. Only by systematically activating the endogenous forces of the community and establishing the community order can the community realize its self-operation during the epidemic period.

\section{RESEARCH METHOD AND PROCESS}

In the investigation and research, this paper aims to grasp the current situation of community governance during the epidemic, and analyze the main manifestations and causes of community governance problems during the epidemic through the specific data obtained from questionnaires and interviews, so as to provide a realistic basis for the exploration of solutions. The following 
methods are mainly used in the investigation and research:

\subsection{Literature research method}

This paper consulted professional books, periodicals and academic papers related to community governance, carefully sorted out, analysed and summarized them, constructed a research framework, and laid a foundation for research by connecting with the actual situation of community governance during the epidemic period.

\subsection{Semi-structured interview}

On the basis of the previous literature research, the author conducted a semi-structured interview with three community workers from April 2020 to May 2020. The measures taken by the community during the epidemic period were deeply understood within the community, and the completeness of the data was ensured from the micro perspective while the research was carried out at the macro level.

\subsection{Questionnaire survey}

This study is for undergraduate students, using online questionnaire survey, 121 questionnaires were sent out, 116 questionnaires were effectively recovered. The ratio of boys to girls was 23:38. Although this survey method has no regional restrictions and low cost, due to the particularity of the network questionnaire survey, the factors affecting the questionnaire response and the quality of the questionnaire response cannot be controlled. But using online questionnaires during an epidemic is the best way to do it.

In this study, we observed and coded the records for qualitative analysis. The collected questionnaires were calculated according to the scoring algorithm of the scale and compared with the norm. After the interview, the recording files were processed and the text materials were sorted out for qualitative analysis.

\section{THE MANIFESTATION OF COMMUNITY GOVERNANCE ISSUES DURING THE EPIDEMIC}

\subsection{The governance efficiency of grass-roots street governments is insufficient}

The government and its staff pay attention to the form in their work, which leads to the low efficiency of community governance and cannot really effectively solve the problems raised by the masses. In addition, in the participatory observation, although there is unified propaganda in the community where the author is an intern, this kind of publicity is only superficial. In an interview, said a staff member said, "because we live in this community compared to other local scope is larger, and the professionalism of the staff is not high, there is no professional community social workers, only has three community members of the staff and residents' committees, for such an emergency we can take actions really rare".

\subsection{Over-administration of mass autonomous organizations}

The over administration of community autonomy. In such a relatively authoritative network as community, government always plays a more important and decisive role than autonomy, which makes the level of community autonomy insufficient and over administration. During the epidemic period appeared the community party organization and community neighbourhood committee park ability is weak phenomenon. Community residents regard epidemic prevention and control as an individual task, rather than a task that requires the joint efforts of the whole community. Community cohesion is poor, and many communities have failed to recruit volunteers and party members to play a pioneering and exemplary role.

\subsection{The supply of community public services is insufficient}

During the epidemic period, when time is tight, and there are few people in the task, which leads to little that the community can do in the epidemic prevention and control. Many communities restrict travel and do not provide material support, leading to doubts about the ability of community autonomy.

Questionnaires were used to identify the measures taken by each community during the outbreak. Of the 122 questionnaires, 11 were answered by community addresses in Hubei Province, while the rest were mainly in Shandong, Henan and Hebei provinces. During the epidemic period, within the scope of our investigation, $92.1 \%$ of communities restricted the number and time of travel at the community entrance and exit, and all communities in Hubei Province restricted travel during the survey. In addition, $83.9 \%$ of the communities that participated in the survey had set up temperature measurement at the entrances and exits, and only $30.7 \%$ of the communities had recruited community residents to participate in the epidemic prevention and control work, and the main work was still undertaken by community workers and neighbourhood committee members. Community resources are seriously inadequate. It is reported that there is about one community worker for every 700 people in Wuhan, and there are only 10 community workers for every 10,000 people in actual operation. In the critical period of epidemic prevention and control, there is a serious shortage of community workers under this configuration. 


\section{CAUSE ANALYSIS OF COMMUNITY GOVERNANCE PROBLEMS DURING THE EPIDEMIC}

\subsection{The general framework of community governance has not been completed}

In China, the transition time from street to community is not long, and many conditions in the transition period are not mature, and the institutional factors of the government and the technical operation of the market have not reached maturity. Therefore, China's governance is still in the transition stage, and the general framework of community governance has not been completed. Other community governance is not perfect system, community public management rules and regulations is not sound, no emergency linkage mechanism of community governance, community to epidemic prevention and control work, can't really do it will force to sink at the grass-roots level, thus produced due to the unclear function, unclear responsibilities and lead to the problem of "community"[7]. In this reality, making community governance more difficult, it is easy to produce more governance problems.

\subsection{Self-organizing developmental retardation}

Beyond the scope of community practice the responsibility with the west, in the Chinese community governance problems to show the failed to fully exercise their powers, making the community can only is not fully play, thus formed the community governance power security administration guide this kind of situation, cause the reality of community diversity management main body role away from its role ought to be ${ }^{[8]}$.

As a result, the allocation of power is more focused on the government, which makes it difficult for selforganizations to develop independently, resulting in blurred boundaries between social organizations and state organizations, and the danger of repeating national administrative omnipotence. As a result, the allocation of power is more focused on the government, which makes it difficult for self-organizations to develop independently, resulting in blurred boundaries between social organizations and state organizations, and the danger of repeating national administrative omnipotence [9].

\subsection{Low participation of community residents}

The legitimacy of community public management is insufficient, which leads to the lack of mass foundation for the operation of community power and the low degree of participation of community residents. Many community residents believe that what we should do is to cooperate, rather than regard ourselves as a member of the main body responsible for the prevention and control of the epidemic in the community. The community residents' participation in the community is very low, resulting in the weak public awareness of the community residents, the lack of a sense of belonging to the community. This makes community governance activities lose their vitality and further centralize community power, which greatly affects the development of community democratic governance and the spread of community epidemic prevention work ${ }^{[10]}$. During the epidemic period, the community lacked residents to participate in the epidemic prevention and control work as volunteers, or even recruited no volunteers. Residents of each community take the prevention and control of the epidemic as an individual task, but do not consider the community as a whole, to which we all belong.

\section{CONCLUSION}

In this paper, using the data obtained from participation observation, semi-structured interview and questionnaire, we analyse the situation of community governance during the epidemic, and draw the following conclusions: because the current general framework of community governance has not been completed, the power allocation is too concentrated on administrative forces, self-organization is slow to develop, and at the same time, people's support is lacking, so the function of community governance has not been fully exerted during the epidemic. The problems of community governance can be attributed to many aspects. To solve the problems of community governance during the epidemic period, many parties should cooperate and solve them together.

There are still some defects and regrets in this study. For example, in the research object, there are only three community workers, and the data sources are limited to the self-expression of social workers and the author's observation, lacking the third-party perspective and the supplement of more case data, so the accuracy, reliability and popularization of the research will be limited to some extent.

\section{REFERENCES}

[1] Announcement of the National Health Commission of the People's Republic of China [J]. Chinese Health Law,2020,28(02):24.

[2] Wang Defu. Global Times,2020-02-06(007). Community epidemic prevention and control should strengthen the weak links.

[3] David Easton. The Political System: An Inquiry into the State of Political Science. New York: Knopf. 1971.pp.121-134

[4] Yang Haitao, Li Dezhi. Research on the failure of community governance from the perspective of policy network $[\mathrm{J}]$. Journal of Northeastern 
University (Social Science Edition), 2010,12 (06):529-534.

[5] Dong H D. Building a community bastion for epidemic prevention and control $[\mathrm{N}]$. Jilin Daily,2020-02-20(012).

[6] Cheng H. It is very important to build community epidemic prevention and control fortress [N]. People's Court Daily,2020-02-18(002).

[7] Jin Jiahou, Wu Xinye. Community governance: Reflections on the theory and practice of "community failure" [J]. Guangdong Social Sciences,2002(05):133-138.

[8] MIAO Xiaohui. Civil society capital and urban community governance $[\mathrm{J}]$. Science and Education Guide (mid-day issue),2011(03):150-151.

[9] Wang Zhenhai. On the Politics of Community: Social Change Quietly Conducted Around People [M]. Taiyuan: Shanxi People's Publishing House, 2003:124

[10]. Liu Yuchen. Urban community democratic governance from the perspective of power reconstruction [J]. Theoretical Guide,2010(02):5153. 